Received Date : 14-Apr-2016

Revised Date : 21-Jun-2016

Accepted Date : 29-Jun-2016

Article type : Original Research: Empirical research - quantitative

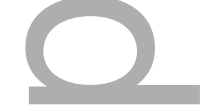

Corresponding author mail id : richardgray@ucalgary.ca

\title{
The effect of Nurse GraduaTeness on patient mortality: a cross sectional survey (the NuGaT study)
}

Ioannis GKANTARAS PhD Researcher ${ }^{1}$, Ziyad R HAHFOUD PhD Associate Professor2, Brent FOREMAN RN MSc Assistant Executive Director ${ }^{1}$, David R THOMPSON RN PhD Professor ${ }^{5}$, Ann Marie CANNABY RN PhD Chief Nurse ${ }^{1}$, Deepak Hanmanthrao DESHPANDE MSc Data Manager ${ }^{1}$, Roger WATSON RN PhD Professor $^{3}$, Annie TOPPING RN PhD Assistant Executive Director ${ }^{1,6}$, Richard GRAY RN PhD Professor 1, 5,6

1. Hamad Medical Corporation, Doha, Qatar

2. Weill Cornell Medical College, Doha, Qatar

3. The University of Hull, Hull, UK

4. The Australian Catholic University, Melbourne, Australia

5. The University of South Australia, Adelaide, Australia

6. The University of Calgary, Qatar

\section{Running head}

This is the author manuscript accepted for publication and has undergone full peer review but has not been through the copyediting, typesetting, pagination and proofreading process, which may lead to differences between this version and the Version of Record. Please cite this article as doi: 10.1111/jan.13059

This article is protected by copyright. All rights reserved 
Nurse graduateness and patient mortality

\section{Acknowledgements}

We would like to thank Paul Halliday and Akram Mostafa Ibraheem, director of Health Information Management and HR ERP teams respectively for their contribution in providing access to the relevant data sources and their continuous commitment to excellence at Hamad Medical Corporation. Without their assistance the particular research project could have been materialized.

\section{Conflicts of interest}

No conflict of interest was declared by the authors in relation to the study itself. Note that Roger Watson is JANs Editor-in-Chief but, in line with usual practice, this paper was subjected to double blind peer review and was edited by another editor.

\section{Funding}

The funding for this research was provided by the Qatar Academic Health System, Health Services and Population Health Research Program Grant. The aim of this program is to stimulate independent and high quality research on areas that affect the health of the population of Qatar.

\section{Author Contributions}

All authors have agreed on the final version and meet at least one of the following criteria (recommended by the ICMJE*):

1) substantial contributions to conception and design, acquisition of data, or analysis and interpretation of data;

2) drafting the article or revising it critically for important intellectual content.

* http://www.icmje.org/recommendations/

\section{ABSTRACT}


Aim. To investigate the relationship between patient mortality and the educational preparation (graduateness) of the nurses who cared for them.

Background. There have been 18 studies over the last two decades examining the effect of nurses' educational qualifications on mortality. All but three have used mortality data aggregated at the hospital level that has been combined with surveys of nurses to estimate the level of graduateness in the population. Data collection and extraction generally has been done at different points in time.

Design A retrospective, cross sectional study.

Method Routine administrative patient data were extracted (May - August 2015). The primary outcome was all-cause patient mortality at discharge. We were able to identify the individual nurses who provided care during patients inpatient stay using an identification number. We were then able to calculate the 'graduateness' of the nursing care patients received by dividing the number of recorded episodes of care provided by baccalaureate prepared nurses with the total number of care episodes.

Results. After adjusting for confounding, we observed a significant association between patient mortality and nurse graduateness. Our observations suggest an optimum level of baccalaureate prepared nurses of approximately $70 \%$. Above this level there appears to be no additional decrease in mortality rates.

Conclusion. This study represents an important methodological step forward over previous approaches. Our observations are generally consistent with existing literature and confirm the importance of baccalaureate nurse education.

Keywords: nurse, graduateness, mortality, cross-sectional, survey, Qatar, RN4CAST

Registration Number of Study (clinicaltrials.gov): 15363/15

SUMMMARY STATEMENT

Why is this research needed?

This article is protected by copyright. All rights reserved 
- The level of graduateness of nursing staff has been shown to be related to patient mortality

- Staffing levels have been shown to be related to patient mortality

- Previous studies have used aggregated data to investigate the above phenomena

\section{What are the key findings?}

- This study used data that relates individual patients to individual nurses

- This study confirms the observations made regarding levels of graduateness of nursing staff and the relationship to patient mortality

- This study uses a more robust measure of graduateness of nurses than previous studies

\section{How the findings should be used to influence policy, practice and research}

- Evidence is provided to support adequate levels of Registered Nurses in clinical practice to decrease patient mortality

- Evidence is provided to support further programs to increase numbers of graduate Registered Nurses in clinical practice

- Further research is necessary into the meaning of graduateness among Registered Nurses

\section{Introduction}

Nursing is integral to the safe and effective operation of any modern health system (Van De Heede et al. 2009, p. 2) and its effectiveness is directly linked to the competence of the nursing workforce and the quality of the care they provide. Over the past 20 years the impact on patient outcomes of the educational preparation of nurses has been studied in some detail (Adams et al. 1997, Aiken et al. 2014). Of particular interest has been the effect of baccalaureate (or higher) level preparation for nurses compared with diploma or certificate education. Several authors have described this as the graduateness (the proportion of baccalaureate prepared nurses) of the nursing workforce (Stacey et al. 2015). There is some ambiguity with this definition; some nurses, for example, may start diploma level training and already 
hold a baccalaureate or Masters degree, would they be considered graduate nurses (by virtue of their previous education) or not?

\section{Background}

We reviewed the literature and identified 18 observational studies that have tested the association between nurse graduateness and patient mortality (see supplementary document). Most (13 out of 18) report a positive association. However, there are important methodological threats to the external validity of some of these studies (e.g. Aiken et al.2011, Dilles et al. 2010, Estabrooks et al. 2015, Kutney-Lee et al. 2013). Perhaps the most substantial issue is that in many studies, the nurses who participated in the research were not necessarily those who provided direct care to participating patients. For example in the largest and most recent study of this type-RN4CAST the authors state that patient mortality data were extracted for the year most proximate to the nurse survey (Sermeus et al. 2011). Nurses are a dynamic workforce and frequently change jobs and roles. It seems logical to us to posit, at least, that many of the nurses in the survey were not the same as those who provided direct care to included patients.

The precision of measurement of nurse graduateness has also been challenged (Aiken et al. 2015). The percentage of nurses in the RN4CAST study with a baccalaureate degree was determined using a self-report survey methodology. This is problematic for two main reasons. First, self-report may lend itself to a high degree of social desirability bias i.e. 'I should have a degree so it's best I tick that box'. Second, the reported average response rate of $62 \%$ (Kutney-Lee et al. 2013), suggests significant non-response bias. Aiken et al. (2015) argue that this is typical in this kind of research; however, even if this is true it does not mitigate the real possibility of measurement error (Ridley et al. 2008, p. 152).

To date all but one (Sasichay-Akkadechanunt et al. 2003) of the previous studies of nurse graduateness have been undertaken in North America and Europe. It might be reasonable to assume there is only marginal variability in the quality and outcome of a baccalaureate education in these countries. In the Middle East most of the Registered Nurses are educated in countries such as India and the Philippines, with developing educational and health systems. We have no high quality evidence confirming that the 
benefits of graduateness on clinical outcomes are maintained in these countries. In addition, we do not believe that it is acceptable, blindly, to generalize observations made in countries with emerging health systems and compare to those with profoundly different levels of economic and social capital.

\section{The Study}

\section{Aims}

Using linked nurse and patient data, the objective of this study was to assess the effect of the graduateness of nursing care on all-cause patient mortality.

\section{Design}

A retrospective, cross-sectional study. We have reported our study according to STROBE guidelines (Von Elm et al. 2007). De-identified patient and nurse data were extracted (May -August, 2015) from administrative sources of seven out of eight major public hospitals in Qatar. Participating hospitals had a total of 1,720 beds and admitted 264,138 patients in 2015. The state health system employed 8,695 nurses the majority $(93 \%)$ were trained outside of the country.

\section{Participants}

We included all patients, of any age, admitted for at least one day, to any ward (e.g. medical, surgical, pediatric, oncology, cardiovascular) during the study period. We included all nurses recorded on the electronic patient record that provide care for included patients. We excluded patients admitted through the accident and emergency department because of the high risk of death without exposure to direct nursing care. All patients admitted to the facility that used the old Electronic Medical Record system have been automatically excluded since their records did not contain the corporate identification of the nurses involved in the episode.

\section{Data collection}

$\underline{\text { Wards }}$

Nurse satisfaction data were available at the ward level only and were obtained through the National Database of Nursing Quality Indicators (NDNQI®) RN Survey with Job Satisfaction Scales@ (RNS-JSS), during October 2014. The RNS-JSS 
contains items from the NDNQI-Adapted Index of Work Satisfaction (Stamps, 1997; Taunton et al. 2004), NDNQI-Adapted Nursing Work Index (Aiken \& Patrician, 2000) and Job Enjoyment (adapted from Brayfield \& Rothe, 1951, Taunton et al. 2004), work context items, as well as several nurse characteristic items, which were not all relevant to our nursing workforce. The measure is used extensively and has internationally established validity (Boyle et al. 2006). The NDNQI® provided data at a facility and ward level, which includes the subscales of: Task, Nurse-Nurse Interaction, Nurse-Physician Interaction, Decision-Making, Autonomy, Professional Status, Pay, Nurse Management, Nursing Administration, Professional Development Opportunity and Professional Development Access. This survey is a revision of the NDNQI Adapted Job Satisfaction Scales, reducing the number of subscales, while maintaining reliability and validity (NDNQI 2016).

\section{$\underline{\text { Nurses }}$}

We extracted data on the educational preparation of all nurses' working in the health system. An independent credentialing department is responsible for checking the authenticity and probity of the qualifications of all employed nurses. Before being submitted for credentialing, certificates need to have been legally attested, giving our measure of graduateness a high degree of face validity. Nurses were classified as graduates in this study if they held a baccalaureate or higher degree in a health related subject. Additionally, we collected data on nurses' age, gender and nationality. We also generated an aggregated nurse-staffing ratio (calculated on a daily basis for the four month study period) by dividing the total number of nurses and the number of inpatients present during that day. This is a routine way of calculating staffing ratios in research although different measures are often used operationally (Kutney-Lee et al. 2013, p. 581, Aiken et al. 2012, p. 4).

\section{$\underline{\text { Patients }}$}

We extracted data on patients' age, gender, nationality, length of inpatient stay and diagnosis priority (recorded on scale from 1 (low)-5 (high)), the latter is an indication of acuity of the patient's condition at the point of admission. We also calculated for each included patient the graduateness of nurses providing their care. In this study the dependent variable was mortality defined as death at discharge. 


\section{Ethical considerations}

The study was reviewed and approved by the local Institutional Review Board (IRB, $15363 / 15)$.

\section{Data analysis}

The nurses' identification number was used to link nurse and patient records. We manually excluded records with incomplete or inaccurate data; this included missing nurse identification number, education data or negative length of stay (This might happen when an incorrect admission or discharge date is entered into the patient administration system). This is common and advisable practice with this type of data analysis (Sales 2008, p. 939). Although there were 8,695 nurses in the employment records, only 5,296 provided direct patient care in the seven hospitals included in our study. The rest have been automatically discarded from the study population since their corporate identification numbers were not linked to any patient encounter. The data preparation process is shown in Figure 1.

\section{Outcomes}

The initial stage of the study involved the extraction of patient clinical and demographic data (that included the ID number of nurses providing direct patient care) from the administrative information systems for a period of four months, starting 1 May 2015. We also extracted nurses' data from a separate administrative database. We then linked the two datasets together using the nurses' ID number (which appears in both datasets). Patients inevitably receive care from more than one nurse during an inpatient stay. We computed the proportion of the nurses educated to at least bachelor level as an estimate of the graduateness of the nursing care each patient received. We did the same with the nurses' age, as a marker (albeit limited) of the clinical experience of those involved in each patient's admission.

Following the data processing, we arrived at a final data set that included demographic and clinical information about each patient, the graduateness of the nursing care they received, the satisfaction of the nurses providing care and staffing ratios in individual units. Apart from age we were not able to include any other nurse demographic information in the data set. 


\section{Addressing the risk of bias}

We tried to eliminate bias by extracting a fairly inclusive and representative sample of patient records from all available hospitals only excluding accident and emergency admissions. Standard data checking and cleaning procedures were followed (Benchimol 2015, p. 13). We excluded records with missing data, e.g. missing patient age, we assumed that the reasons for records being incomplete were random and there was no systematic reason as to why this may have occurred.

We estimated that the minimum sample size should be between 1,941-2,101 patients, depending on the method of calculation, Kelsey or Fleiss algorithms respectively (Sullivan, et al. 2007). That was calculated using a 95\% CI, 80\% power, ratio of unexposed to exposed (3213/4109), estimated percent of unexposed with outcome of interest (mortality) approximately (64/3213) and percent of exposed with outcome (190/4109).

\section{$\underline{\text { Statistical Methods }}$}

We used multiple bivariate and one multivariable logistic regression to test our hypotheses and to identify which parameters and to what extent they affect patient mortality, in unadjusted and adjusted models. For the trend analysis and the relationship between patient mortality and education we have used a polynomial regression model, as shown in Figure 2.

We planned to adjust for several potential confounders that have been identified in previous studies. We conducted three separate logistic regression experiments to test the relationship between patient mortality and graduateness adjusting for patient (age, length of stay, diagnosis priority) and/or nurse (age - as a proxy for experience, staffing ratio and satisfaction) confounding variables. Analyses were done using IBMSPSS (version 21, Armonk, NY: IBM Corp., USA). A p-value of 0.05 or less was considered statistically significant.

\section{Results}

A total of 7,322 patient records that were linked to aggregate nurse data comprised our dataset. Over the four months of the study $688(9.85 \%)$ patients were readmitted and 254 died (3.47\%). The average staffing ratio (8.96 patients per nurse) and 
mortality rate were unremarkable in comparison to European countries (Aiken et al. 2014). There was a total of 5,296 nurses that were involved in providing care to these patients. The study population hierarchy is shown in Figure 3.

\section{Participants}

The demographic characteristics of patients are shown in Table 1. Generally patients were mostly female, in their mid-thirties, from South East Asia, spending just over two days in hospital, with illnesses that were not considered critical. Nurses were almost exclusively female, also in their mid-30s; just over half were trained in South East Asia. There was an almost equal split between those who were baccalaureate and non-baccalaureate trained (Table 2) and the average satisfaction was high, 3.88/5. Staff turnover was low; over the study period 33 nurses left the health system, which represents $0.37 \%$ of the total nursing workforce. Based on these data we estimate a turnover rate of around $1 \%$ per year across the national health system, this is exceptionally low. We conducted three separate logistic regression experiments (SPSS v21) to test the relationship between patient mortality and graduateness adjusting for patient (age, length of stay, diagnosis priority) and nurse (age, staffing ratio and satisfaction) confounding variables.

\section{Outcome data}

In total, $254(3.47 \%)$ patients died over the four month period of the study. The demographic and clinical profile of these patients was different to those who were discharged alive (Table 1). Those who died (numerically) were more likely to be male, older — more than 38 years of age — and with a higher diagnosis priority.

\section{Main results}

The estimates of the relationship between mortality and nurse graduateness are shown in Table 3. As might be expected diagnosis priority, p <0.001, OR=5.984, 95\% $\mathrm{CI}=4.630,7.734$, nurse education $\mathrm{p}=0.013, \mathrm{OR}=0.990,95 \% \mathrm{CI}=0.982,0.998$ and staffing, $\mathrm{p}<0.001, \mathrm{OR}=0.067,95 \% \mathrm{CI}=0.041,0.113$, were significantly associated with patient mortality, (Table 3). Nurses' age and their level of work satisfaction were found to be not significantly associated, $\mathrm{p}=0.177, \mathrm{OR}=0.965,95 \% \mathrm{CI}=0.916,1.016$ and $\mathrm{p}=0.210, \mathrm{OR}=0.437,95 \% \mathrm{CI}=0.120,1.592$ respectively. The descriptive statistics of all the adjusted model variables are shown in Table 4. 
Figure 2 shows the relationship between mortality and graduateness. The red line is the optimum trend line that mathematically describes the relationship and equivalent distribution. To generate this graph we calculated several daily patient mortality figures by dividing the number of patients who died with the number of patients present on any ward on that particular date. Those figures were plotted against the relevant graduateness figures that were calculated by dividing the number of nurses with a degree with the total number of nurses that were involved in the treatment of those patients. The equation for the regression trend line can be used to approximately calculate the required education level to decrease mortality to a certain degree. The value of the coefficient of determination, $\mathrm{R}^{2}=0.894$, indicates that there is a fairly good fit between the generated model equation and the actual values, that allows us to calculate safe predictions.

\section{Supplementary analyses}

We also examined the relationship between staffing ratios and mortality. In both the unadjusted and adjusted models we observed that staffing ratios were significantly associated with patient mortality (Tables $3 \& 5$ ).

\section{Discussion}

The aim of this study was to test the association between graduateness and mortality in an emerging health system. Our observation was consistent with the majority of previous studies (for example Yakusheva et al. 2014, Blegen et al. 2013, Kutney-Lee et al. 2013) that have shown a clear effect of graduate education on mortality. The odds ratio in our study was somewhat more modest than larger studies in established and mature health systems (e.g. Aiken et al. 2014). To date, only one study (SasichayAkkadechanun et al. 2003) has involved nurses trained in countries with developing educational systems (particularly India and the Philippines). It is important to confirm that graduate education in these countries results in a comparable reduction in mortality. Simply put, we need to check that graduate education for nurses has value wherever in the world that education takes place. Our observations are consistent with this hypothesis and suggest that the effect of graduateness is a generalizable observation internationally. 
Our study has important methodological novelty. The deterministic binding of two separate electronic data sets distinguishes our study from previous research (Sales et al. 2008, Sermeus et al. 2011, Blegen et al. 2013). It is a valid criticism that graduateness is a proxy measure of the quality of the care provided by the entire health system (not just nursing). In this study, because we were focused on nurses who actually provided the care to patients, we have strengthened the (external) validity of the observation.

Our approach to measuring the graduateness of nurses is noteworthy and was calculated as follows: If a patient was cared for by five nurses during their hospital admission and three of them were bachelor prepared we calculated that the graduateness of the nursing care they received as $60 \%$ (3/5 x 100). A similar ratio can be calculated for each facility or ward but calculating that for each patient provides us with a higher attributability of our exposure, nurse education, to mortality. We are not relying on self-report survey methodology that is prone to significant bias (Lucero et al. 2010, McHugh et al. 2014, Aiken et al. 2011) we extracted data from the databases that contained the verified qualifications of nurses working in the health systems. Whilst this approach conveys significant advantages we did have issues in determining the level of educational preparation of some of the nurses and this may have led to bachelor educated RNs being inadvertently included in the non-graduate group. For example, bachelor degrees acquired after initial RN education studied through distance and/or blended learning modes are not presently recognized as graduate nurses in the State of Qatar.

It is important to note that Registered Nurses provided all the nursing care delivered in this study and that this was a stable workforce over time (i.e. staff turnover was low). The health system does not routinely employ nursing or health care assistants and the nursing workforce is almost exclusively qualified nurses. Consequently, the nursing care that is provided is not diluted by care from unqualified staff. In our view this study is, therefore, a more robust evaluation of the effect of graduateness.

The results of our study suggest that, as the graduateness of the nursing workforce increases, mortality declines. Whilst this study is not powered to examine statistically this relationship our data suggests that there may be an optimum level of 
graduateness. Mortality falls under $2 \%$ when the graduateness reaches around $44 \%$ and to $1 \%$ at approximately $70 \%$. After that the patient mortality stabilizes at around $0.8 \%$. Our data suggests that above $70 \%$ graduateness confers no appreciable benefits (in terms of mortality). It is worth noting that this figure is below the $80 \%$ graduate level recommended by the ANCC Magnet program. Larger studies adopting our methodology will be able to estimate more precisely the optimum level of graduateness in the nursing workforce.

Our observation that staffing ratios have an impact on patient mortality is consistent with previous research (Lucero et al. 2010, Ma et al. 2015). We also followed the same logic in the calculation of those by using the number of nurses and patients cared for on the last shift in each hospital (McHugh et al. 2013, p. 3). In our case, the standard length of a shift is 8 hours.

\section{Limitations}

Whilst we have attempted to adjust for previously reported confounders in this field of enquiry it remains possible that our observed association may be explained by unknown confounding factors. For example, it may be that baccalaureate nurse education attracts a different type of person (in terms of performance at high school, sense of autonomy) to study nursing. The characteristics of participants before they started nursing were not well understood. It seems to us that research teams need to better understand and assess potential differences between these two groups of nurses when conducting future studies. We used nurse age as an estimate of their length of clinical experience. This may be reasonable if it is assumed that nurses come straight from school into nurse training. This may be true for the majority of our sample, however in other countries this is patently not the case; many nurses come into training as a later in life. Future studies would be enhanced if this were more accurately measured.

Nurse satisfaction was determined via an annual survey conducted in October 2014 using a standard measure. Our survey comprises a sufficient number of responses and the results are normally distributed (Van den Heede et al. 2009, p. 2). The response rate in the survey was exceptionally high (93\%) compared with similar studies of this type (Kelly et al. 2014, Ma et al. 2015) possibly because the nurses might have felt 
obliged to complete this. However, the data do not provide any evidence this actually occurred.

\section{Further research}

Low staff turnover and high nurse satisfaction might suggest a workforce that is not fearful in reporting errors. The relationship between satisfaction, turnover and patient outcomes would be an important area for further investigation. To avoid biasing our observation we excluded all Accident and Emergency admissions where the death of the patient was highly likely. However, we did include patients, for example with terminal cancer, where death was expected. However it is difficult to determine accurately patients who were expected to die. It may be a more conservative approach to consider excluding all cancer patients from any future research.

\section{Conclusion}

The nursing workforce is the backbone of every modern health system. Whilst the observation that the graduateness of nurses impacts on patient mortality is not in itself novel this study contributes to knowledge in three important ways: First, we have-for the first time-shown a direct link between nurses who provided care and mortality in the patients they looked after. Second, we have shown that nurses who have earned their degrees from countries with emerging educational systems still have a positive impact on patient outcomes. Third we confirm the conclusion of most previous studies about value of graduateness to a health system. Additionally we have raised some important questions about the optimum ratio of graduate nurses in the workforce.

\section{Additional Information}

\section{Funding}

The funding for this research was provided by the Qatar Academic Health System, Health Services and Population Health Research Program Grant. The aim of this program is to stimulate independent and high quality research on areas that affect the health of the population of Qatar.

\section{Resources Accessibility}

This article is protected by copyright. All rights reserved 
Access to the study protocol, the original data, the programming code implemented to extract and integrate the data or the methodology that was followed to produce the final research dataset is available on request.

\section{Acknowledgements}

We would additionally like to thank Paul Halliday and Akram Mostafa, directors of Information Management and Human Resources departments respectively for their permission, assistance and guidance in using the Data Warehouse and Oracle HR database data for that project.

\section{Conflict of interest}

Roger Watson, Editor-in-Chief, has acted in the capacity of a funded academic visitor to the Hamad Medical Corporation, Doha, Qatar

\section{References}

Adams M.M., Wilson H.G., Casto D.L., Berg C.J., McDermott J.M., Gaudino J.A., McCarthy B.J. (1997) Constructing reproductive histories by linking vital records. American Journal of Epidemiology 145 (4), 339-348.

Aiken L.H., Cimiotti J.P., Sloane D.M., Smith H.L., Flynn L., Neff D.F. (2011) The effects of nurse staffing and nurse education on patient deaths in hospitals with different nurse work environments, Medical Care 49(12), 1047-1053.

Aiken L.H., Clarke S.P., Cheung R.B., Sloane D.M., Silber J.H. (2003) Educational levels of hospital nurses and surgical patient mortality. Journal of the American Medical Association 290(12), 1617-1623.

Aiken L. H., Patrician P. A. (2000) Measuring organizational traits of hospitals: the Revised Nursing Work Index. Nursing Research 49(3), 146-153.

Aiken L.H., Sloane D., Bruyneel L., Van den Heede K., Griffiths P., Busse R. (2014) Nurse staffing and education and hospital mortality in nine European countries: a retrospective observational study. The Lancet 383 (9931), 1824-1830. 
Blegen M.A., Goode C.J., Park S.H., Vaughn T., Spetz J. (2013) Baccalaureate education in nursing and patient outcomes. Journal Nurse Administration 43(2), 89-94.

Boyle D. K., Miller P. A., Gajewski B. J., Hart S. E., Dunton N. (2006) Unit type differences in RN workgroup job satisfaction. Western Journal of Nursing Research 28 (6), 622-640.

Brayfield A. H., Rothe, H. F. (1951) An index of job satisfaction. Journal of Applied Psychology 35(5), 307-311

Dilles T., Vander Stichele R., Van Rompaey B., Van Bortel L., Elseviers, M. (2010) Nurses practices in pharmacotherapy and their association with educational level. Journal of Advanced Nursing 66(5), 1072-1079.

Estabrooks C.A., Midodzi W.K., Cummings G.G., Ricker K.L., Giovannetti P., (2005) The impact of hospital nursing characteristics on 30-day mortality. Journal of Advanced Nursing 54(2), 74-84.

Kelly D.M., Kutney-Lee A., McHugh M.D., Sloane D.M., Aiken L.H. (2014) Impact of critical care nursing on 30-day mortality of mechanically ventilated older adults. Critical Care Medicine 42(5), 1089-95.

Kutney-Lee A., Aiken L.H. (2009) Effect of nurse staffing and education on the outcomes of surgical patients with comorbid serious mental illness. Psychiatric Services 59(12), 1466-1469.

Kutney-Lee A., Sloane D.M. and Aiken L.H. (2013) An increase in the number of nurses with baccalaureate degrees is linked to lower rates of postsurgery mortality. Health Affairs 32(3), 579-586.

Lucero R., Lake E.T., Aiken L.H. (2010) Nursing care quality and adverse events in US hospitals. Journal Clinical Nursing 19, 2185-2195. 
Ma C., McHugh M.D, (2015) Organization of hospital nursing and 30-day readmissions in Medicare patients undergoing surgery. Medical Care 53, 382-8.

McHugh M.D., Kelly L.A., Smith H.L., Wu E.S., Vanak J.M., Aiken L.H. (2013) Lower mortality in magnet hospitals. Medical Care 51(5), 382-8.

Ridley R.T. (2008) The relationship between nurse education level and patient safety: an integrative review. Journal of Nurse Education 47, 149-156.

Sales A., Sharp N., Li Y.F., Lowy E., Greiner G., Liu C.F.( 2008) The association between nursing factors and patient mortality in the Veterans Health Administration: the view from the nursing unit level. Medical Care 46(9), 938-45.

Sullivan, K. Soe, M. (2007). 'Documentation for Sample Size for an Unmatched Case-Control Study' Available at: http://www.openepi.com/SampleSize/SSCohort.htm [accessed: 30 May 2016].

Sasichay-Akkadechanunt T, Scalzi CC, Jawad AF. The relationship between nurse staffing and patient outcomes. Journal of Nursing Administration 2003; 33(9): 478-85.

Sermeus W, Aiken L H, Van den Heede K, Rafferty A M, Griffiths P, MorenoCasbas M T, Busse R, Lindqvist R, Scott A P, Bruyneel L, Brzostek T, Kinnunen J, Schubert M, Schoonhoven L, Zikos D and RN4CAST consortium (2011) Nurse forecasting in Europe (RN4CAST): Rationale, design and methodology, $B M C$ Nursing 10(6).

Stacey G, Pollock K, Crawford P (2015) A case study exploring the experience of graduate entry nursing students when learning in practice. Journal of Advanced Nursing 71(9), 2084-2095. 
Taunton R. L., Bott M. J., Koehn M. L.; Miller P., Rindner E., Pace K., Elliott C., Bradley K. J., Boyle D, Dunton, N. (2004) The NDNQI-Adapted Index of Work Satisfaction. Journal of Nursing Measurement 12(22), 101-122.

Van den Heede K., Lesaffre E., Diyab L., Vleugelsa A., Clarked S. P., Aiken L. H., Sermeus W. (2009) The relationship between inpatient cardiac surgery mortality and nurse numbers and educational level: Analysis of administrative data. International Journal of Nursing Studies 46(6), 796-803.

Von Elm E., Altman D.G., Egger M., Pocock S. J., Gøtzsche P. C., Vandenbroucke J. P. (2007) The Strengthening the Reporting of Observational Studies in Epidemiology (STROBE) Statement: Guidelines for reporting observational studies. Preventive Medicine 45(7), 247-251.

West E., Mays N., Rafferty A.M., Rowan K., Sanderson C. (2009) Nursing resources and patient outcomes in intensive care: a systematic review of the literature. International Journal of Nursing Studies 46(7), 993-1011.

Yakusheva O., Lindrooth R., Weiss M. (2014) Economic evaluation of the $80 \%$ baccalaureate nurse workforce recommendation: a patient-level analysis, Medical Care 52(10), 864-9. 
Table 1. Patient counts and percentages by gender, nationality groups and discharge result.

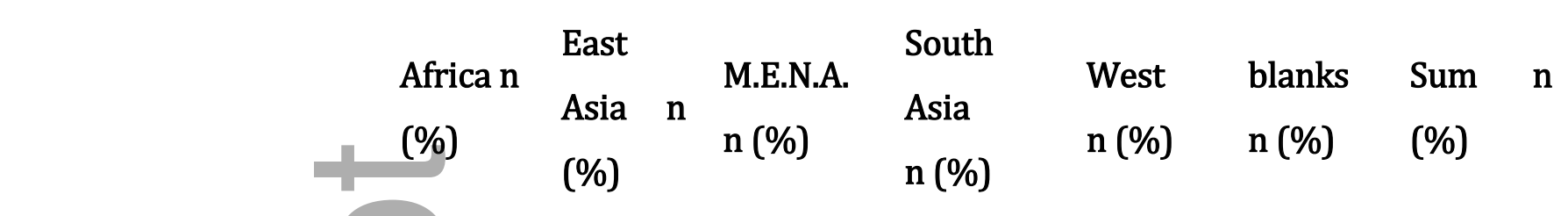

Yes: 254/ 1.99\%

$\begin{array}{lrrrrrrr}\text { Male: } & & & & & & & \\ 136 & 9 & 62 & 37 & 2 & 0 & 145 \\ 1.99 \% & (0.48 \%) & (0.12) & (0.85 \%) & (0.51 \%) & (0.03 \%) & (0.0 \%) & (1.98 \%)\end{array}$

7322

Overall

$\begin{array}{lrrrrrrr}\text { Female: } & 5 & 2 & 73 & 23 & 6 & 0 & 109 \\ 109, & (0.07 \%) & (0.03 \%) & (1 \%) & (0.31 \%) & (0.08 \%) & (0.0 \%) & (1.49 \%) \\ 1.48 \% & & & & & & \\ \text { Male: } & & & & & & & 1 \\ 1859, & (1.34 \%) & (1.02 \%) & (12.14 \%) & (10.12 \%) & (0.75 \%) & (0.01 \%) & (25.39 \%) \\ 6.13 \% & \end{array}$

7068/7322 Female:

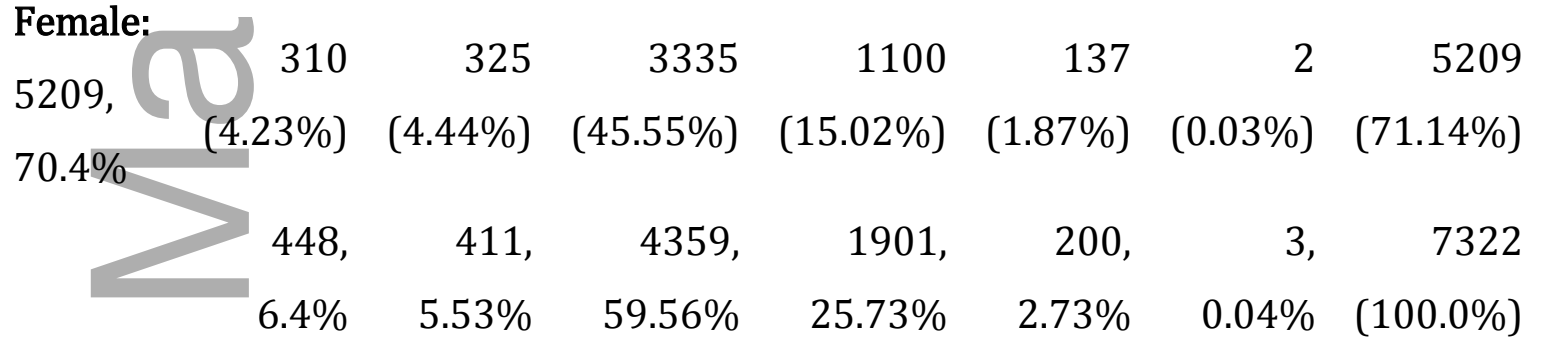

This article is protected by copyright. All rights reserved 
Table 2. Numbers and percentages of graduate and non-graduate nurses by nationality groups. The total number of nurses, 5296, has been used to calculate the percentages in all cases.

$\begin{array}{llll}\text { Nationality } & \text { Graduate } & \text { Non-Graduate } & \text { Total } \\ \text { Africa } & 22(0.42 \%) & 69(1.30 \%) & 91(1.72 \%) \\ \text { East Asia } & 465(8.78 \%) & 739(13.95 \%) & 1204(22.73 \%) \\ \text { South Asia } & 1602(30.25 \%) & 1755(33.14 \%) & 3357(63.39 \%) \\ \text { M.E.N.A.[1] } & 204(3.85 \%) & 398(7.52 \%) & 602(11.37 \%) \\ \text { West } & 33(0.62 \%) & 9(0.17 \%) & 42(0.79 \%) \\ \text { Total } & 2326(43.92 \%) & 2970(56.08 \%) & 5296(100 \%) \\ \text { Gender (M/F) } & 217 / 2109 & 282 / 2688 & 498 / 4798 \\ \text { Age (Mean, } & 35.51,6.26 & 36.5,9.01 & 36.06,8.35 \\ \text { S.D.) } & & & \end{array}$

[1] Middle East and North Africa

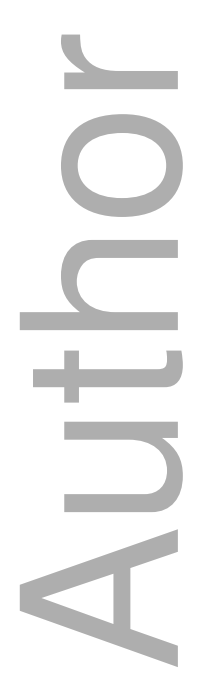

This article is protected by copyright. All rights reserved 
Table 3. Adjusted Logistic Regression results for patient mortality and its relationship with all the model variables.

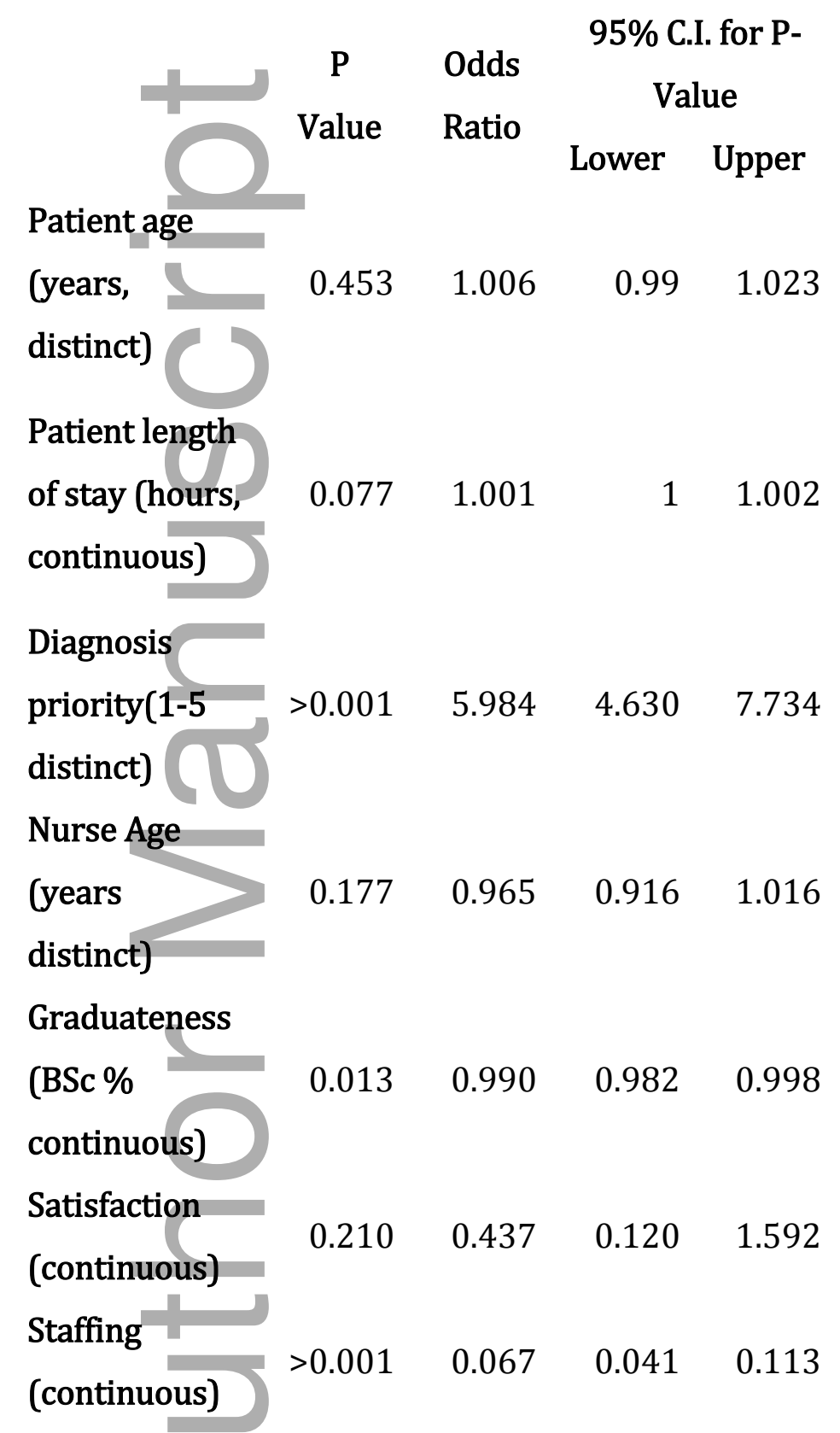

This article is protected by copyright. All rights reserved 
Table 4. Descriptive results of all the numerical model variables.

\begin{tabular}{lrrrrrr} 
& \multicolumn{1}{c}{ Mean } & Median & Mode & St. Deviation & Minimum & Maximum \\
Patient age (years) & 35.38 & 34 & 30 & 14.56 & 0 & 93 \\
Patient length of stay & & & & & & \\
(hours) & 49.13 & 31 & 0 & 145.36 & 0 & 2132 \\
Diagnosis priority & 0.11 & 0 & 0 & 0.66 & 0 & 5 \\
Nurse experience (years) & 37.14 & 36.5 & 29 & 6.68 & 27 & 58 \\
Nurse education (BSc \%) & 0.40 & 0.33 & 0 & 0.42 & 0 & 1 \\
Nurse satisfaction (1-5) & 3.95 & 3.95 & 3.95 & 0.19 & 3.44 & 4.28 \\
Nurse staffing & 8.97 & 9 & 9 & 0.66 & 5.95 & 10.63
\end{tabular}

This article is protected by copyright. All rights reserved 
Table 5. Summary of adjusted and unadjusted logistic regression results for patient mortality and its relationship to nurse graduateness, satisfaction and staffing.

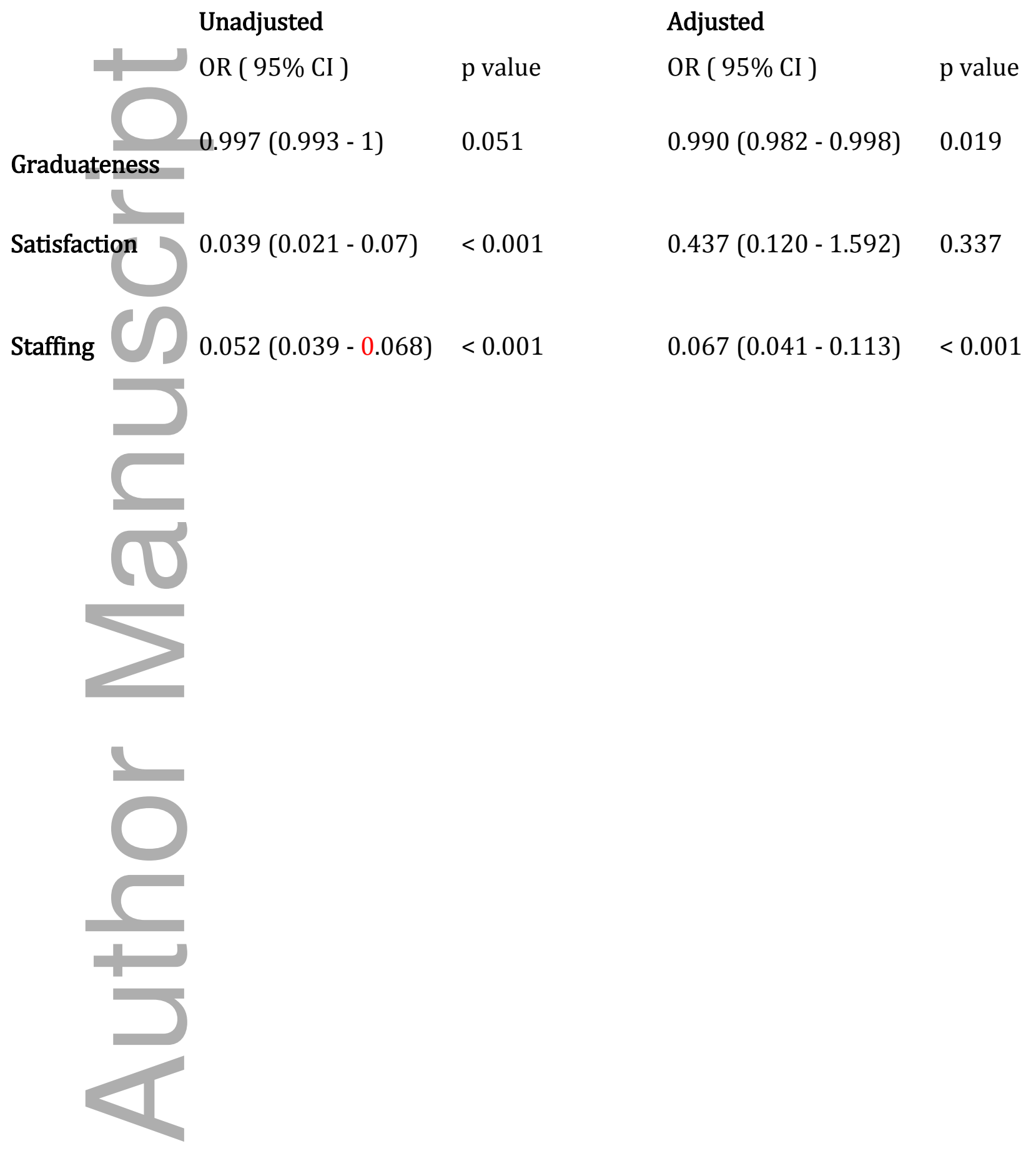




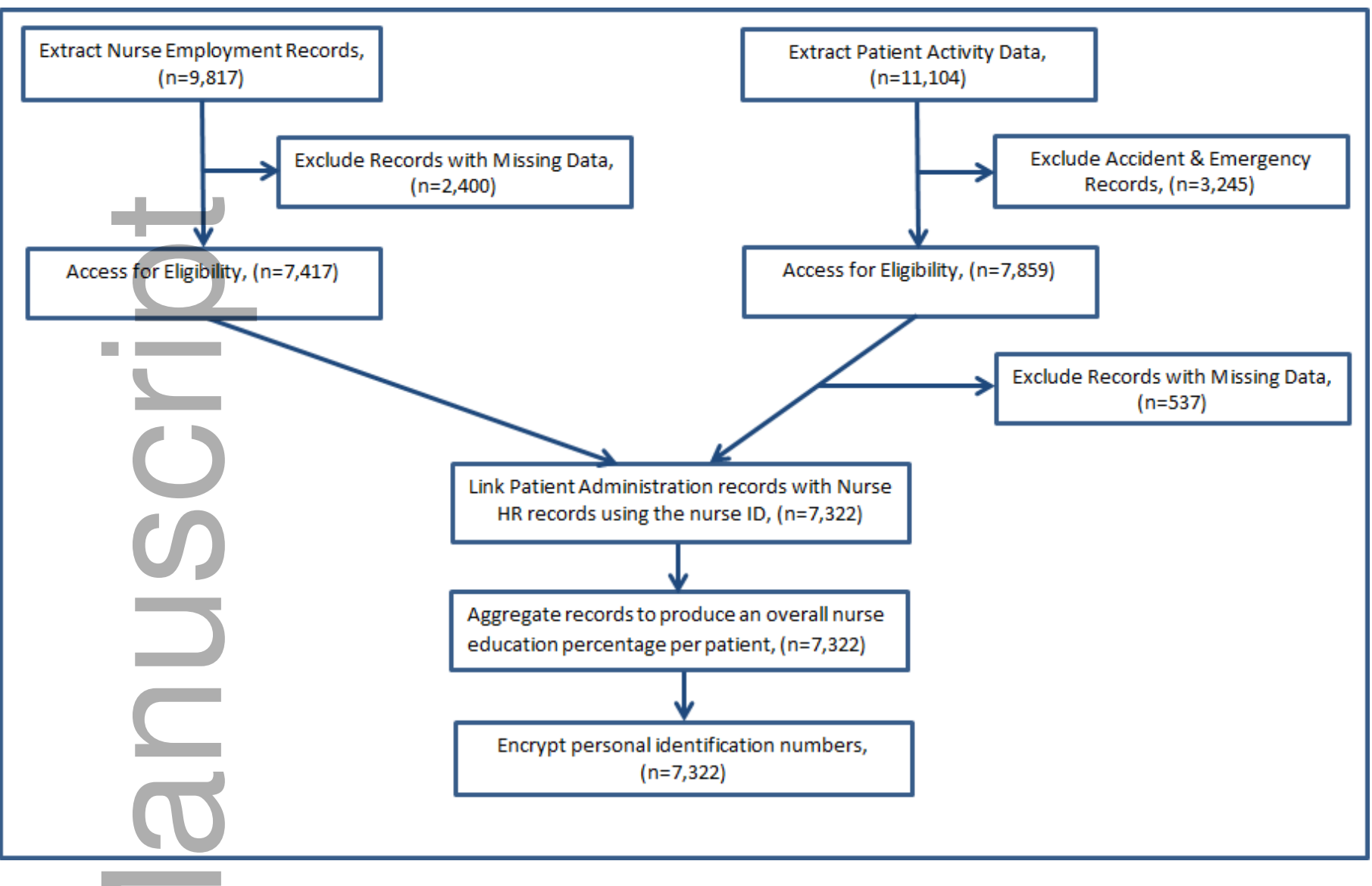

Figure 1. Flow diagram of the data extraction, cleansing, merging and preparation process and the subsequent figures of records. 


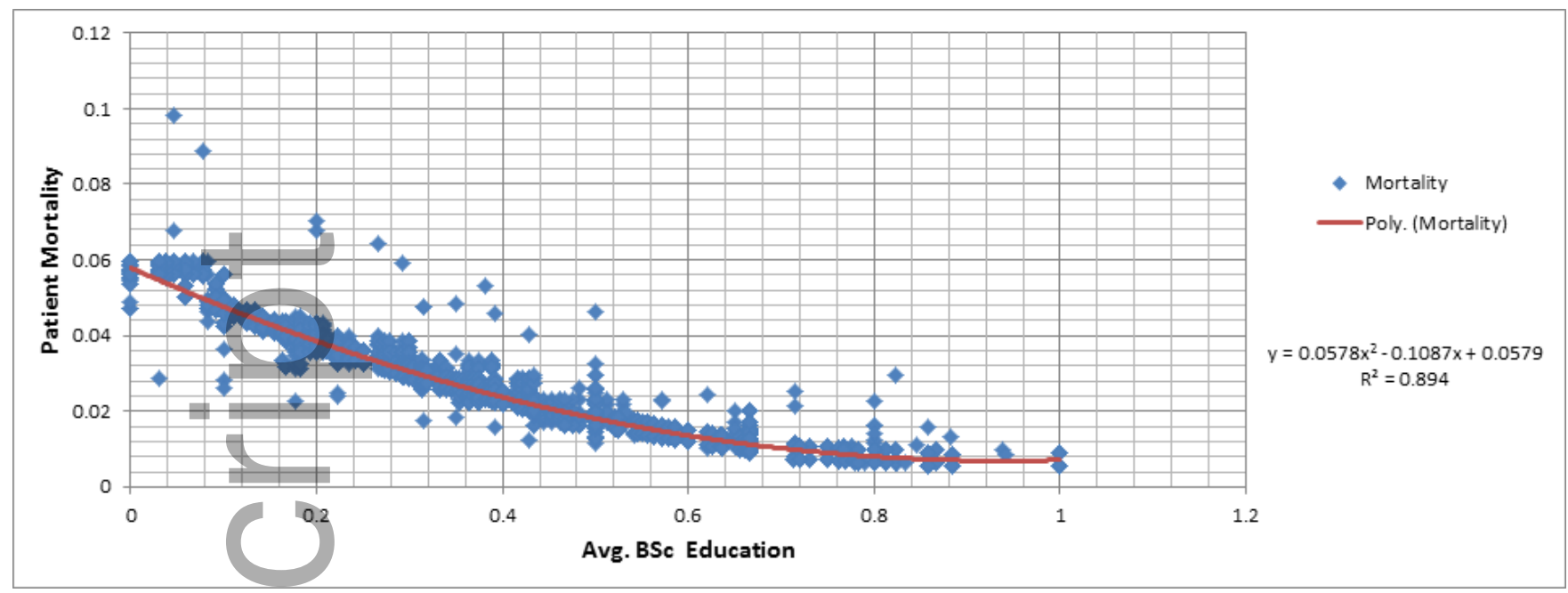

Figure 2. Scatter plot depicting the relationship between patient mortality and nurse education to graduate level and the optimum trend line that mathematically describes that relationship and equivalent distribution.

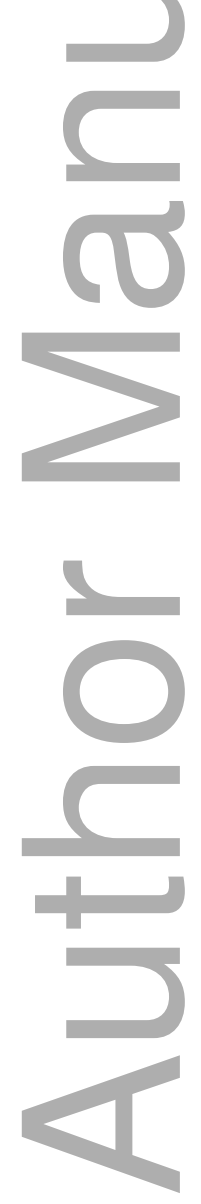

This article is protected by copyright. All rights reserved 


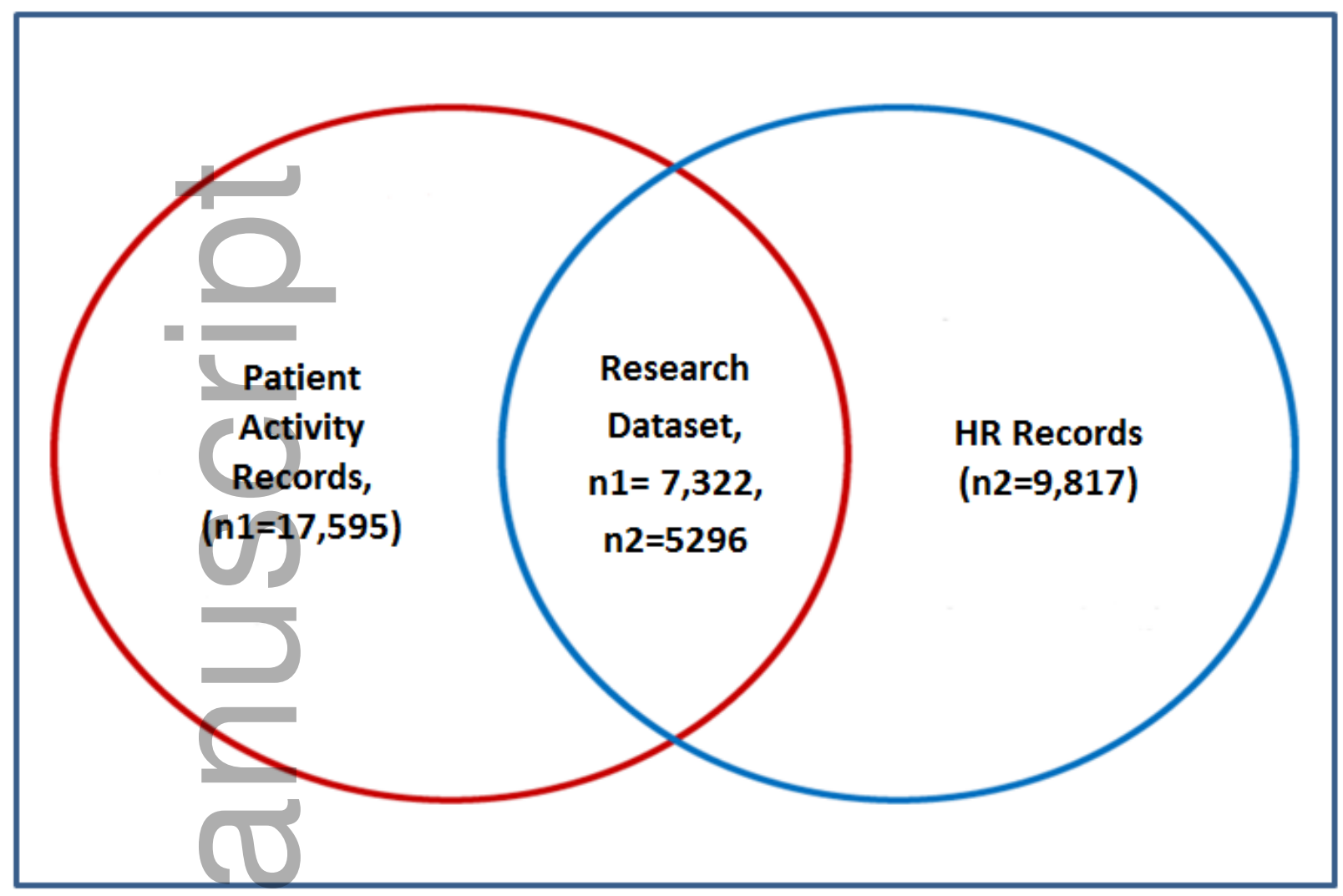

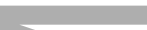

Source Population: Population of Qatar

Database Population: Patient Activity Records and Human Resources nurse employment Records

Study Population: Intersection of Patient Activity and HR Records - Research Dataset

Figure 3. Venn diagram that depicts the linkage process, the nurse and patient populations and the creation of research dataset as apart their intersection.

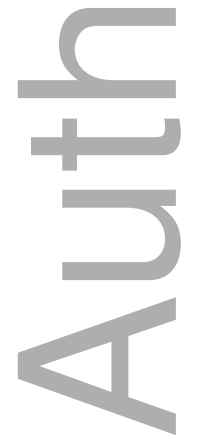




\section{University Library}

\section{- M M N E R VA A gateway to Melbourne's research publications}

Minerva Access is the Institutional Repository of The University of Melbourne

\section{Author/s:}

Gkantaras, I;Mahfoud, ZR;Foreman, B;Thompson, DR;Cannaby, AM;Deshpande, DH;Watson, R; Topping, A;Gray, R

Title:

The effect of Nurse GraduaTeness on patient mortality: a cross-sectional survey (the NuGaT study)

Date:

2016-12-01

Citation:

Gkantaras, I., Mahfoud, Z. R., Foreman, B., Thompson, D. R., Cannaby, A. M., Deshpande, D. H., Watson, R., Topping, A. \& Gray, R. (2016). The effect of Nurse GraduaTeness on patient mortality: a cross-sectional survey (the NuGaT study). JOURNAL OF ADVANCED NURSING, 72 (12), pp.3034-3044. https://doi.org/10.1111/jan.13059.

Persistent Link:

http://hdl.handle.net/11343/291552 